\title{
HOMENS E MULHERES EM VIVÊNCIA DE VIOLÊNCIA CONJUGAL: CARACTERÍSTICAS SOCIOECONÔMICAS ${ }^{a}$
}

\author{
Nadirlene Pereira GOMES ${ }^{\mathrm{b}}$, Normélia Maria Freire DINIZ \\ Climene Laura de CAMARGO ${ }^{b}$, Marieve Pereira da SILVA
}

\section{RESUMO}

Estudo quantitativo, descritivo, com o objetivo de identificar características socioeconômicas de mulheres e homens com história de violência conjugal em Salvador. Realizou-se entrevista com 50 homens e 50 mulheres. Quase todos se autodeclaram negros. Poucos concluíram o ensino médio. Os homens exercem ocupações no espaço do público e as mulheres realizam atividades predominantemente domésticas, mesmo fora de casa. Apenas 3 mulheres (6\%) consideram-se independentes economicamente. Isso tem relação direta com o nível de escolaridade, por constituir-se pré-requisito para entrada no mercado de trabalho. A situação é pior para as mulheres pesquisadas, visto o pequeno número de anos de estudos e o alto grau de dependência financeira, que interfere no seu empoderamento para o enfrentamento da violência conjugal. Os profissionais de saúde, em especial da enfermagem, devem contemplar as iniquidades sociais e valorizar o contexto socioeconômico dos usuários no sentido de identificar situações que comprometam a condição de saúde da população.

Descritores: Violência. Violência contra a mulher. Enfermagem. Políticas Públicas.

\section{RESUMEN}

Estudio cuantitativo, descriptivo con el objetivo de identificar características socio-económicas de las mujeres y los hombres con un historial de violencia doméstica. Hemos llevado a cabo entrevistas con 50 hombres y 50 mujeres. Casi todos los sujetos se autodeclaran negros. La mayoría no terminó la escuela secundaria. Los hombres ejercen ocupaciones que son públicas y las mujeres realizan actividades domésticas. Sólo 3 mujeres (6\%) se consideran independientes económicamente. El grado de dependencia económica está relacionado con el nivel de educación que se constituye como un requisito para la entrada en el mercado laboral. La situación es todavía más precaria para las mujeres con pocos años de estudios y un alto grado de dependencia financiera lo que interfiere con su empoderamiento para enfrentar la violencia conyugal. Los profesionales de la salud, deben abordar las desigualdades sociales para identificar situaciones que pongan en peligro el estado de salud de la población.

Descriptores: Violencia. Violencia contra la mujer. Enfermería. Políticas públicas.

Título: Hombres y mujeres que viven en violencia conyugal: aspectos socioeconómicos.

\section{ABSTRACT}

Quantitative and descriptive study aiming to identify socioeconomic characteristics of men and women with a history of domestic violence. We conducted interviews with 50 men and 50 women. Nearly all subjects were self-declared black. Most did not have too many years of school education. Men perform occupations that are public and women do predominantly domestic activities. Only 3 women (6\%) are considered financially independent. The degree of economic dependence is directly related to the level of education that has been established as a prerequisite to enter into the labor market. The situation is even more precarious for women interviewed with fewer years of education and a high degree of financial dependence that interferes with their empowerment to address domestic violence. Health professionals, especially nurses, should address the social inequities and improve the socioeconomic context of users to identify situations that endanger the health of the population.

Descriptors: Violence. Violence against women. Nursing. Public policies.

Title: Men and women living in marital violence: socioeconomic aspects.

a Artigo originado da tese de Doutorado apresentada em 2009 ao Programa de Pós-Graduação em Enfermagem (PPGEnf) da Universidade Federal da Bahia (UFBA), Salvador, Bahia, Brasil.

b Doutora de Enfermagem, Docente Adjunta da UFBA, Salvador, Bahia, Brasil.

c Mestra em Enfermagem, Enfermeira do Programa de Saúde da Família, Simões Filho, Bahia, Brasil. 


\section{INTRODUÇÃO}

A violência contra a mulher é uma violação dos direitos humanos que traz repercussões físicas e psicológicas, sendo fator de risco para o desenvolvimento de diversos problemas de saúde, o que explica os altos custos sobre a produção econômi$\mathrm{ca}^{(1,2,3)}$. Na América Latina, 25 a 50\% das mulheres sofrem violência doméstica, resultando em 14,2\% de diminuição do Produto Interno Bruto (PIB) e especificamente no Brasil, em 2004, foram gastos com a violência, 90,2 bilhões de reais, o equivalente a $5 \%$ do $\mathrm{PIB}^{(4)}$.

Dados revelam que violência responde por aproximadamente $7 \%$ de todas as mortes de mulheres entre 15 a 44 anos no mundo todo. Especificamente no Brasil, aproximadamente $20 \mathrm{mil}$ mulheres morreram entre 2003 e 2007 por causa da violência ${ }^{(5)}$.

Nacionais ou não, os estudos revelam que o número de casos de violência contra a mulher vem crescendo no âmbito doméstico e que os agressores são homens com quem esta mantém, ou manteve, relação afetiva ${ }^{(4,6,7,8)}$. Segundo dados da Secretaria de Políticas para as mulheres, 38.020 das mulheres são agredidas diariamente no Brasil, e em $68,8 \%$ dos casos os agressores são os cônjuges, companheiros ou ex-maridos ${ }^{(6)}$.

Reichenheim et al..$^{(1)}$ consideram que as principais vítimas da violência doméstica são crianças e mulheres negras e pobres e que a "violência entre parceiros íntimos segue um padrão regional, com prevalência mais elevada nas regiões norte e nordeste - as menos desenvolvidas, onde prevalece uma cultura patriarcal marcante e caracterizada pela desigualdade de gêneros", sinalizando assim para as iniqüidades por raça/etnia, gênero e situação econômica que afetam de sobremaneira a população feminina.

As divergências por raça/etnia e gênero desencadeiam grandes desigualdades entre os estratos sociais e econômicos da população brasileira afetando, sobretudo mulheres, crianças e adolescentes, sendo essenciais ações políticas de combate as iniqüidades baseadas na evidência ${ }^{(9)}$.

A violência se torna um problema que nos diz respeito seja na condição de técnicos, prestadores de assistência à saúde ou estudiosos. Em qualquer dessas atuações, um olhar cuidadoso para os sujeitos e a reflexão constante do exercício ético-político de nossas práticas profissionais são elementos fundamentais para a construção de novos conhecimentos acerca do complexo fenômeno da violência conjugal, bem como para a busca de estratégias de enfrentamento ${ }^{(10)}$.

Diante o exposto, o estudo objetiva identificar as características sócio-econômicas de mulheres e homens com história de violência conjugal.

\section{METODOLOGIA}

Trata-se de um estudo descritivo, com abordagem quantitativa, originado da tese de Doutorado apresentada em 2009 ao Programa de Pós-Graduação em Enfermagem da Universidade Federal da Bahia $^{(11)}$. Considera-se estudo quantitativo-descritivo as pesquisas empíricas que tem como foco a análise ou delineamento das características de um determinado fenômeno, a partir da relação pertinente entre variáveis potencialmente relevantes ${ }^{(12)}$.

O estudo foi realizado com mulheres e homens com história de violência conjugal residentes em uma comunidade localizada em um bairro periférico da cidade de Salvador (BA), com grande dificuldade econômico-social. A aproximação com a comunidade se deu com o apoio de uma associação sem fins lucrativos, criada em 1992 em decorrência da alta incidência de violência doméstica, o que justifica a escolha desse espaço como cenário para a realização do estudo. Essa associação vem sendo, desde 1998, espaço de desenvolvimento de atividades de pesquisa e extensão (Doutorado, Mestrado e Graduação) vinculadas aos grupos de pesquisa cadastrados no CNPq, Grupo de Estudos sobre Saúde da Mulher e Grupo de Pesquisa Violência, Saúde e Qualidade de Vida, da Escola de Enfermagem da Universidade Federal da Bahia.

Um dos projetos de extensão, realizado a partir de oficinas educativas e grupos focais sobre temas da comunidade (drogas, câncer de próstata/ mama, relação familiar, etc) permitiu identificar pessoas em situação de violência conjugal. Vale referir que dentre os homens e mulheres que participavam do projeto, todos vivenciavam ou já vivenciaram situações de violência conjugal, embora alguns não tivessem, até então, a percepção de tal condição. Essa técnica possibilitou ainda desvelar o envolvimento de homens em atividades ilícitas, tais como: roubo de banco e tráfico de drogas.

Como critérios para inclusão dos sujeitos, foram considerados: residir no referido bairro, ser maior de 18 anos, estar em situação de conjugalidade e em vivência de violência conjugal. 


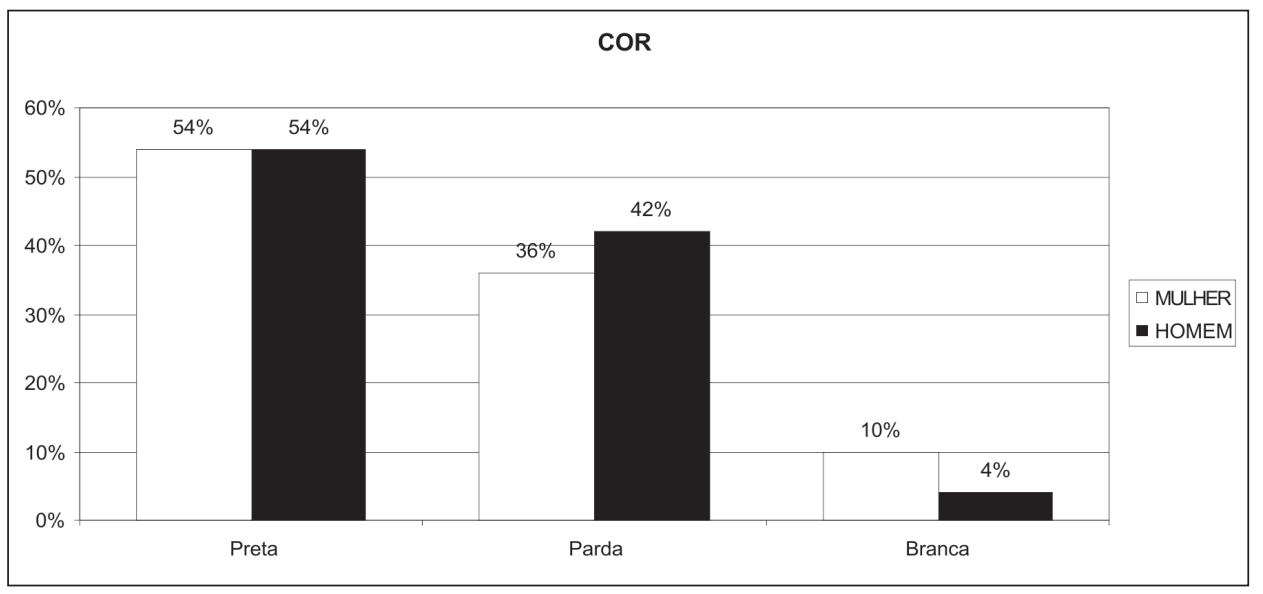

Gráfico 1 - Cor da pele de mulheres e homens. Salvador, BA, 09/2007-02/2008.

Vale salientar que o estudo não teve como foco homens e mulheres conjugues ou que partilhassem de relação afetiva. A amostra, não probabilista, foi composta por 50 mulheres e 50 homens com história de violência conjugal.

Após a aprovação do projeto pelo Comitê de Ética em Pesquisa - Hospital Santo Antônio, sob $n^{\circ} 31 / 07$, mulheres e homens foram informados a respeito do objetivo, da justificativa, da relevância do estudo e de outros aspectos éticos, com base na Resolução 196/96 do Conselho Nacional de Saúde. Esta consiste em diretrizes e normas que regulam as pesquisas com os seres humanos.

Ao aceitarem constituírem-se sujeitos do estudo, mulheres e homens foram solicitados a assinar o Termo de Consentimento Livre e Esclarecido, em duas vias, sendo uma da pesquisadora e outra do sujeito.

Para coleta de dados, realizou-se entrevista estruturada, contendo questões relacionadas com aspectos sócio-econômicos (idade, cor/raça, situação conjugal, escolaridade, situação de trabalho/ emprego e dependência financeira). Essa fase de coleta de dados se deu de forma sistemática entre setembro de 2007 e fevereiro de 2008 e ocorreu no espaço físico da referida associação.

Os dados foram armazenados em bancos de dados utilizando recursos dos programas Microsoft Word e Excel for Windows. Posteriormente, estes foram organizados, tabulados e apresentados sob a forma de gráficos e percentuais descritivos simples.

A análise dos dados fundamentou-se em textos que trata a temática violência à mulher e suas relações com gênero, etnia e políticas públicas.

\section{RESULTADOS}

Dentre os 100 sujeitos com história de violência conjugal, 45 mulheres (90\%) e 48 homens (96\%) são negras(os), auto-declaradas(os) como pretas(os) e pardas(os) (Gráfico 1).

A variável cor deve ser considerada quando se trata de implicações e vulnerabilidade para a vivência de violência. Esta compreensão é fortalecida por outros autores ${ }^{(13)}$ quando referem que, pela influência de aspectos históricos, há uma discriminação alicerçada pelo componente cor. No que tange a violência urbana, os homens negros e pobres, ao mesmo tempo em que são os principais agressores, também são as principais vítimas. Com relação à violência doméstica, estão mais expostas as mulheres e crianças negras e pobres ${ }^{(1)}$. Como os autores da agressão contra a mulher no espaço doméstico são, na maioria das vezes, seus próprios companheiros ${ }^{(4,6,8)}$, o estudo sinaliza para associação entre a categoria raça/etnia e a vivência de violência conjugal por homens e mulheres, seja na condição de vítima ou de agressor.

Especificamente sobre as mulheres, dados fornecidos pela Divisão de Crimes Contra a Mulher, da Polícia Civil, no Pará, na qual foram registradas 8.232 ocorrências de violência contra o sexo feminino apontam as mulheres negras como às principais vítimas ${ }^{(14)}$. Para Oliveira ${ }^{\left({ }^{15}\right)}$, um olhar para a mulher negra permite identificar uma tripla discriminação: por ser mulher, por ser negra e ocupar uma classe social desfavorecida. A discriminação a que está submetida essa parcela da população poderá compreender um fator para a inclusão e vulnerabilidade para a vivência de violência, sendo necessárias políticas focadas para este grupo. 


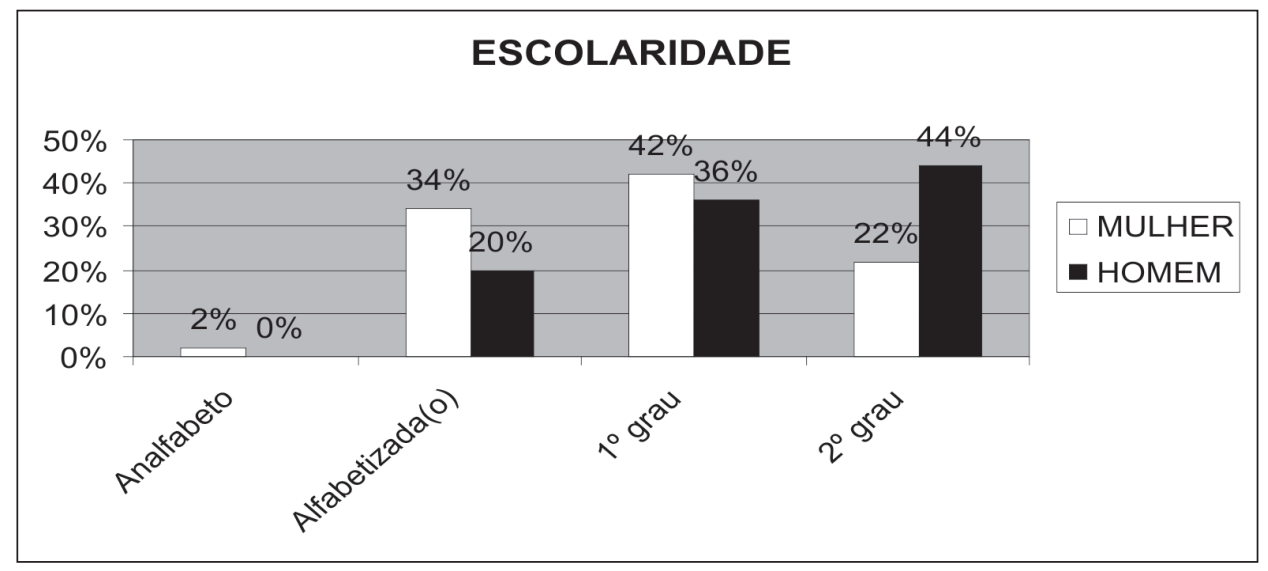

Gráfico 2 - Escolaridade de mulheres e homens. Salvador, BA, 09/2007-02/2008.

Com relação situação conjugal, percebe-se que 34 das 50 mulheres (68\%) e 28 dos 50 homens $(56 \%)$ entrevistados vivem em união estável. Muitos estudos têm considerado o fato de ser casada ou em união estável, como um fator de risco para a vivência de violência doméstica. $\mathrm{O}$ domicílio representa para as mulheres o local onde há maior probabilidade de sofrerem violência, tornando o ambiente privado um espaço de perpetração de ações violentas ${ }^{(12)}$. Contradiz-se, assim, a representação do lar como um espaço de proteção.

Quanto menos desenvolvida a região e menor poder aquisitivo da comunidade, mais marcante é a cultura patriarcal ${ }^{(1)}$. Assim, mais arraigada encontra-se a crença acerca dos papéis de gênero, que reflete a assimetria de poder entre o casal, naturalizando o domínio do homem sobre a esposa e o papel desta na sociedade: casar, cuidar da casa e dos filhos. Essa construção desigual entre os gêneros favorece a construção da violência na relação conjugal e permite compreender a permanência da mulher nesta relação.

Com relação à escolaridade (Gráfico 2), a maioria dos homens $(56 \%, \mathrm{n}=28)$ e sobretudo das mulheres $(78 \%, \mathrm{n}=39)$ entrevistadas não concluíram o ensino médio, considerando que todos tinham acima de 18 anos.

Chama atenção o percentual de homens que completaram o segundo grau $(44 \%, n=22)$ por equivaler ao dobro do percentual de mulheres (22\%, n=11) no mesmo nível de escolaridade. Contraditoriamente, o perfil nacional de escolaridade por sexo revela vantagem para a mulher com uma média de 6,7 anos de estudo sobre o homem com média de 6,4 $\operatorname{anos}^{(16)}$. Essa incongruência pode estar associada à vivência de violência na relação conjugal, sobretudo pelo caráter de privação e limitação das ações das mulheres e/ou ao fato desta constituir família ainda na adolescência, o que dificulta a freqüência escolar.

A população feminina negra, em sua maioria, possui menores anos de escolaridade, tem maiores dificuldades para estudar, ocupa posições mais subalternas, trabalha mais, tem pior salário e condição de trabalho ${ }^{(17)}$.

Os dados quanto à escolaridade das pessoas em situação de violência conjugal são de extrema importância uma vez que, quanto mais esclarecida, por menos tempo a mulher admitirá a violência ${ }^{(18)}$. Pesquisa realizada com 2.128 mulheres em situação de violência por parceiro íntimo revelou que possuir poucos anos de escolaridade é um fator associado à vivência de violência, o que também guarda relação com a naturalização da violência ${ }^{(19)}$. Daí, a dificuldade para romper o ciclo da violência conjugal.

No que se refere à situação de trabalho (Gráfico 3), fica claro a associação do masculino à esfera pública e do feminino, ao âmbito do doméstico.

Do total de homens que trabalham $(64 \%, \mathrm{n}=32)$, todos exercem atividades fora de casa. Vale referir que todas as atividades são tidas como do universo masculino, tais como: pedreiro, carpinteiro e mecânico. Nenhum homem referiu realizar atividades de cunho doméstico, nem mesmo em suas casas.

Em se tratando das mulheres, apenas $36 \%$ $(n=18)$ trabalham fora de casa, sendo que a maioria ocupa funções de cunho doméstico, em especial como empregadas domésticas. Na sua maioria, esses trabalhos referem-se a contratações não formalizadas e, portanto, sem proteção e direitos trabalhistas, deixando as mulheres mais sujeitas às ocupações 


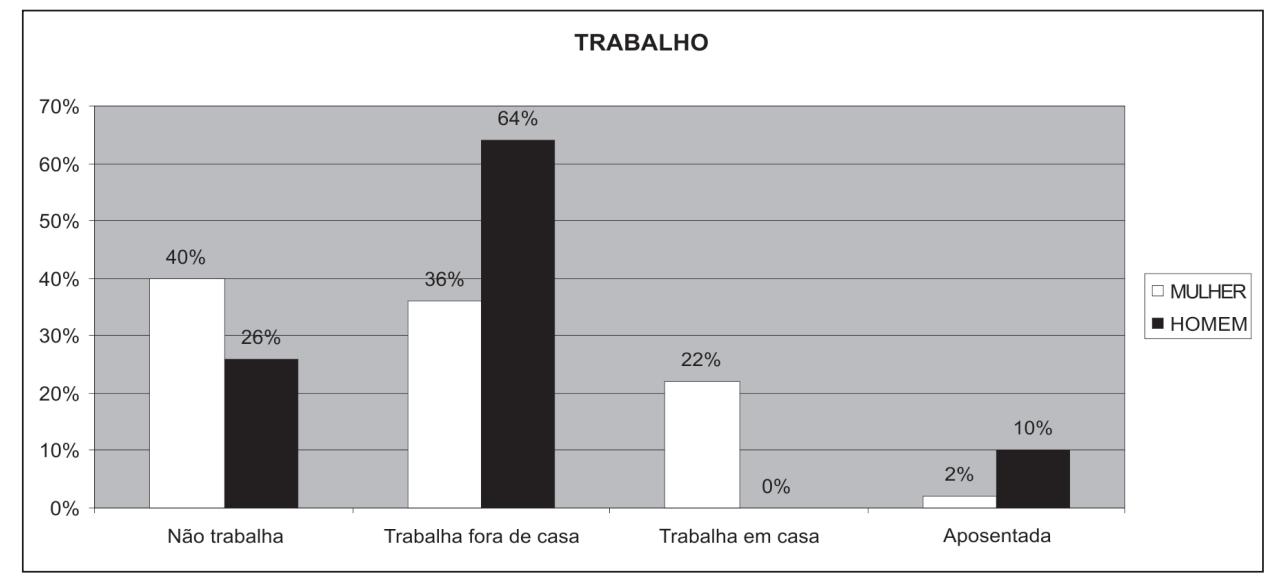

Gráfico 3 -Situação de trabalho/emprego de mulheres e homens. Salvador, BA, 09/2007-02/2008.

com inserção vulnerável. Destacando a ascensão das mulheres brancas sobre as mulheres negras, observa-se que dentro das estatísticas, o emprego doméstico é uma ocupação que absorve $16,5 \%$ das mulheres brasileiras, sobretudo das mulheres negras que recebem renda mensal bem abaixo quando comparado a renda mensal de mulheres brancas ${ }^{(1)}$.

Ainda com relação à ocupação das mulheres, $22 \%(n=11)$ realizam atividades remunerativas sem sair de casa, sendo estas também vinculadas a esfera do doméstico, como por exemplo, crochês, bordados, docinhos, salgados entre outros artefatos para venda externa. As demais mulheres, as aposentadas e as “que não trabalham”, embora não sejam remuneradas, também desenvolvem tarefas domésticas no lar.

Ainda que muitas pesquisas revelem as conquistas das mulheres no que tange a ocupação de espaço antes tido como exclusivo dos homens, nota-se que, neste estudo, não há relatos de inserção das mulheres em atividades tidas do universo masculino. As mulheres entrevistadas sempre realizam as tarefas domésticas em suas casas e dentre as que trabalham fora de casa, quase todas exercem funções domésticas. Este resultado associada a baixa escolaridade das mulheres deste estudo sugerem o pequeno nível de qualificação profissional deste grupo.

Também não se notou a inserção do homem no mundo privado, pois a tarefa doméstica não é desenvolvida, dentro ou fora de casa, por qualquer dos homens entrevistados, de modo que esta, neste estudo, se mostrou eminentemente feminina.

Pesquisa com mulheres vítimas de violência conjugal mostrou que $41,4 \%$ das entrevistadas tinham alguma fonte de renda quando comparado com $74,5 \%$ dos homens agressores ${ }^{(20)}$. No nosso estudo, este percentual foi de $60 \%(\mathrm{n}=30)$ para as mulheres e $74 \%(\mathrm{n}=37)$ para os homens, respectivamente, para mulheres e homens.

Com relação aos desempregos, o estudo mostra o percentual de mulheres $(40 \%, \mathrm{n}=20)$ e homens $(26 \%, n=13)$ sem qualquer fonte de renda. Em maio de 2008, a taxa de desemprego em Salvador também era maior para as mulheres $(25,2 \%)$ do que homens $(16,6 \%)$. Na população negra, a taxa é ainda mais alta $(29,2 \%)$ quando comparado com as pessoas brancas $(16,9 \%)$, o que evidencia que as mulheres negras ocupam posição de maior desemprego ${ }^{(17)}$.

A análise da renda se faz necessária uma vez que estudos apontam que a dificuldade financeira vem sendo fator de desentendimentos e, portanto, motivo para criar situações de conflitos que culminam em agressões no âmbito doméstico ${ }^{(21)}$.

Com relação ao grau de dependência, chama atenção que apesar de $60 \%(\mathrm{n}=30)$ das mulheres referirem alguma fonte de renda, apenas $6 \%(\mathrm{n}=3)$ se consideram independentes financeiramente (Gráfico 4).

Os homens, na sua maioria, declararam-se independentes financeiramente $(72 \%, \mathrm{n}=36)$, ao contrário das mulheres que se declararam parcial $(48 \%, \mathrm{n}=24)$ ou totalmente dependentes $(46 \%, \mathrm{n}=23)$ (Gráfico 4). Quase a totalidade das mulheres depende economicamente do companheiro ou de familiares.

A dependência financeira é um dos motivos relatados pelas mulheres para não deixar seu companheiro, especialmente quando existem filhos, pois sem remuneração, a mulher fica impossibilitada de se auto-sustentar e de sustentar seus filhos ${ }^{(18)}$. O grau de dependência econômica tem relação direta com o nível de escolaridade por constituir-se 


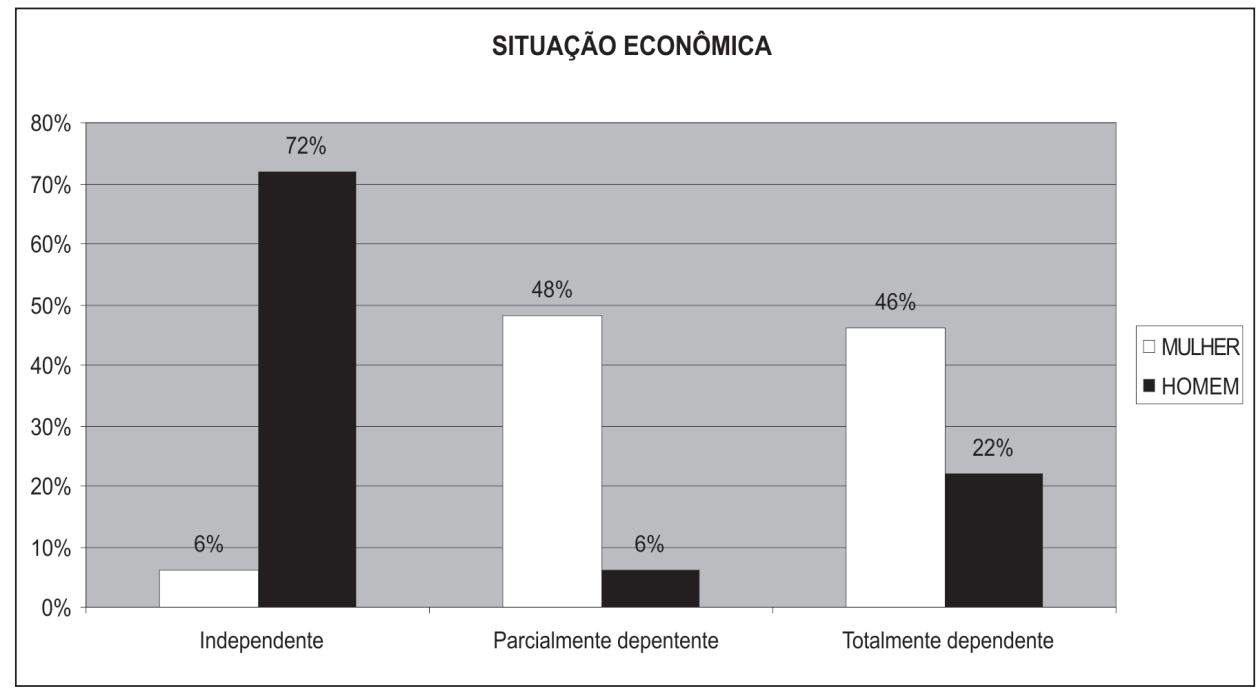

Gráfico 4-Dependência econômica de mulheres e homens. Salvador, BA, 09/2007-02/2008.

pré-requisito para entrada no mercado de trabalho. Entretanto, o preconceito racial também dificulta essa inserção. A população negra recebe tratamento discriminatório tanto nas entrevistas, quando são os excluídos no momento da seleção, quanto já na condição de empregados, quando são os primeiros nas listas de cortes das empresas ${ }^{(17)}$. Estas situações terminam por deixar as mulheres ainda mais vulneráveis a permanecer na relação de violência.

Em outro estudo(21), o papel masculino de provedor do lar e a dependência financeira feminina são colocados como características que fortalecem a aceitação por parte da mulher de seus "deveres conjugais". A dependência econômica, de fato, pode levar a mulher a demorar um período maior para a busca de auxílio( ${ }^{(7)}$. No entanto, casos de violência envolvendo mulheres economicamente independentes, inclusive situações em que os companheiros monopolizam a renda que elas adquirem, desvelando a força da representação do homem enquanto chefe-de-família, independente de quem, de fato, "traga dinheiro para casa”. Necessário se faz a criação novas práticas pedagógicas que promovam uma compreensão mais ampla acerca dos papéis sociais de homens e mulheres e, conseqüentemente, relações mais simétricas.

Especificamente com relação às mulheres, chama atenção para as características socioeconômicos que mostram a baixa escolaridade, a falta de emprego ou sub-empregos e o alto índice de dependência econômica. Essa caracterização corresponde ao perfil das mulheres que entraram em contato com o Ligue 180, responsável por atender mulheres que sofreram agressões e ameaças: maioria negra, casada, possui filhos e com baixa escolaridade ${ }^{(2)}$.

\section{CONSIDERAÇÕES}

Os sujeitos do estudo caracterizam-se por serem mulheres e homens que vivem em união estável cujas relações conjugais são permeadas pela violência. Quase todos se auto-declaram negros. A maioria se quer concluiu o ensino médio. Os homens exercem ocupações tidas masculinas no espaço do público e as mulheres realizam atividades predominantemente domésticas mesmo fora de casa. Apenas 3 mulheres (6\%) consideram-se independentes economicamente.

Sabe-se que a educação constitui um meio para conquista de outros direitos. Como os sujeitos do estudo residem em um bairro periférico da cidade de Salvador (BA), podemos inferir acerca das sérias dificuldades sócio-econômicas vivenciadas, que guardam relação com a vivência/permanência de violência na relação conjugal. Essa experiência no cotidiano destes homens e mulheres eleva o risco de estresse, comprometendo a saúde mental e física de toda a família. Daí a importância de se valorizar, de fato, o contexto sócio-econômico do usuário no momento do atendimento realizado pelos profissionais de saúde, em especial da enfermagem, no sentido de identificar situações que comprometam a condição de saúde da população.

As características sócio-econômicas relacionadas às mulheres e aos homens com história de 
violência conjugal revelam a violação de direitos básicos à educação, emprego e segurança. Esses direitos fazem parte de uma construção histórica, de muitas lutas e conquistas, expressos, em sua forma atual, na Declaração Universal dos Direitos Humanos de 1948. A situação é ainda mais precária para as mulheres pesquisadas, visto o pequeno número de anos de estudos e alto grau de desemprego e dependência financeira, o que interfere no seu empoderamento para o enfrentamento do fenômeno.

Vale dizer que as discriminações de gênero, raça e classe colocam as mulheres negras em situações ainda mais desfavoráveis $(90 \%, \mathrm{n}=2345)$, sinalizando para a necessidade de ações políticas no sentido de garantir o mínimo necessário para assegurar o reconhecimento do valor e da dignidade das mulheres. Nesta perspectiva, as políticas públicas devem se voltar para o combate à discriminação racial, de gênero e para redução das iniqüidades sociais, sendo obrigação do Estado respeitar o princípio da equidade tratando de maneira especial pessoas que historicamente vêm sendo excluídas; e do povo, portanto nossa, se organizar politicamente para reivindicar os direitos, até então, não contemplados e fazer cumprir as políticas já aprovadas.

\section{REFERÊNCIAS}

1 Reichenheim ME, Souza ER, Moraes CL, Jorge MHPM, Silva CMFP, Minayo MCS. Violência e lesões no Brasil: efeitos, avanços alcançados e desafios futuros. The Lancet. 2011 maio; 75-89.

2 Correio da Bahia. Denúncias de violência contra mulher crescem 32\% em 2008 [Internet] Correio da Bahia. 2009 jan 12 [citado 2009 jun 14]. Disponível em: http://www.direitos.org.br/index.php?option= com_content\&task=view\&id $=4838 \&$ Itemid $=2$.

3 Borsoi TS, Brandão ER, Cavalcanti MLT. Ações para o enfrentamento da violência contra a mulher em duas unidades de atenção primária à saúde no município do Rio de Janeiro. Interface Comunic Saúde Educ [Internet]. 2009 jan [citado 2009 nov 20]; 13(28): 165-74. Disponível em: http:// www.scielo.br/scielo.php? script=sci_arttext\&pid $=$ S1414-32832009000100014

4 Silva M. Violência: um problema de saúde pública. In: Conferência Nacional de Saúde Mental. Ministério da Saúde; 2010 jun; Brasília [Internet]. Brasília (DF): MS; 2010 [citado 2011 jun 04]. Disponível em: http://portal.saude.gov.br/portal/arquivos/pdf/ violenciamartasilva.pdf.
5 Meneghel SN, Hirakata VN. Femicídios: homicídios femininos no Brasil. Rev. Saúde Pública. [Internet] 2011 jun [citado 2011 set 04]; 45(3): 564-74. Disponível em: http://www.scielo.br/scielo.php?script=sci_ arttext\&pid=So034-89102011000300015\&tlng=pt

6 Brasil. Secretaria de Políticas para as mulheres (SEPM). Balanço central de Atendimento à Mulher [Internet]. Brasília(DF): Secretaria de Políticas para as Mulheres; 2010. [citado 2011 ago 28]. Disponível em: http://www.sepm.gov.br/noticias/ultimas_noticias/2010/10/ balanco-da-central-de-atendimento-a-mulher.

7 Salvador. SPM promovendo políticas para todas as mulheres: dados estatísticos. [Internet]. 2009 [citado 2009 abr 13]. Disponível em: http://www. spm.salvador.ba.gov.br /index.php?option $=$ com _content\&task.

8 Lisboa M, coordenador. Inquérito Violência de Gênero. SociNova/CesNova: Faculdade de Ciências Sociais e Humanas/Universidade Nova de Lisboa, 2008.

9 Brasil. Comissão Nacional sobre Determinantes Sociais da Saúde. As causas sociais das iniqüidades em saúde no Brasil: Relatório Final da Comissão Nacional sobre Determinantes Sociais da Saúde [Internet]. Brasília (DF): Comissão Nacional sobre Determinantes Sociais da Saúde; 2008. [citado em 2010 jun 10]. Disponível em: http://www.cndss. fiocruz.br/pdf/home/relatorio.pdf.

10 Batista KBC. Violência contra a mulher e Programa Saúde da Família: a emergência da demanda na visão dos profissionais. In: Villela W, Monteiro S. Gênero e Saúde: Programa Saúde da Família em Questão. Rio de Janeiro: Arbeit Factor; 2005. p.119-137.

11 Marconi MA, Lakatos EM. Fundamentos de metodologia cientifica. $7^{\text {a }}$ ed. São Paulo (SP): Atlas; 2010

12. Riscado JLS, Oliveira MAB; Brito AMBB. Vivenciando o Racismo e a Violência: um estudo sobre as vulnerabilidades da mulher negra e a busca de prevenção do HIV/aids em comunidades remanescentes de Quilombos, em Alagoas. Rev. Saúde Soc. [Internet].2010 [citado 2011 set 23]; 19(2): 96-108. Disponível em: http://www.scielo.br/pdf/sausoc/ v19s2/10. pdf

13 Costa M, Gomes G. Dia Internacional de Luta pela não violência à mulher [Internet]. 2007 [citado em 2007 jul 11]. Disponível em: http://www.belem. pa.gov.br/app/paginas/pauta.view.php?id_pau$\mathrm{ta}=42$. 
14 Oliveira MAB. Mulher e violência em Maceió: um pensar sobre sua história [dissertação]. Maceió: Universidade Federal de Alagoas;. 2006.

15 Comissão Interamericana de mulheres. Trigésima Terceira Assembleia de Delegadas [Internet]. 2006 mai. [citado 2008 maio 10]. Disponível em: http:// www.oas.org/es/cim/docs/Brasil2006.pdf

16 Ferreira CDF. Discriminação e preconceito. [Internet]. 2002 [citado 2009 abr 05] Disponível em: http://www.familianegrabrasil.com.br/menu/direitos/direitos.html.

17 Adeodato VG, Carvalho RR, Siqueira VR, Souza FGM. Qualidade de vida e depressão em mulheres vítimas de seus parceiros. Rev Saúde Pública. 2005 fev; 39(1): 108-113.
18 D’Oliveira AFPLucas, Schraiber LB, França-Junior I, Ludermir AB, Portella AP, Diniz CS et al. Fatores associados à violência por parceiro íntimo em mulheres brasileiras. Rev Saúde Pública. [Internet]. $2009 \mathrm{abr}$ [citado 2011 set 23]; 43(2):299-311. Disponível em: http://www.scielo.br/pdf/rsp/2009nahead/7172.pdf

19 Prades PL. Violência Doméstica e de gênero: perfil demográfico e psicossocial de mulheres abrigadas [dissertação]. São Paulo: Faculdade de Saúde Pública da USP; 2007.

20 Rosa AG, Boing AF, Büchele F, Oliveira WF, Coelho EBS. A violência conjugal contra a mulher a partir da ótica do homem autor da violência. Rev Saude soc. [Internet]. 2008 jul [citado em 2011 set 23]. Disponível em: http://www.scielo.br/scielo.php?pid=So 104$-12902008000300015 \&$ script $=$ sci_arttext

\author{
Endereço da autora / Dirección del autor / \\ Author's address: \\ Nadirlene Pereira Gomes \\ Rua Jardim Vera Cruz, Quadra 05, lote 08, IAPI \\ 40340-590, Salvador, BA \\ Email: nadirlenegomes@hotmail.com
}

